\title{
Impacts of Vegetation Change on the Regional Surface Climate: A Scenario-Based Analysis of Afforestation in Jiangxi Province, China
}

\author{
Enjun Ma, ${ }^{1}$ Anping Liu, ${ }^{1}$ Xing Li, ${ }^{1}$ Feng Wu, ${ }^{2}$ and Jinyan $\mathrm{Zhan}^{2}$ \\ ${ }^{1}$ School of Mathematics and Physics, China University of Geosciences (Wuhan), Wuhan 430074, China \\ ${ }^{2}$ State Key Laboratory of Water Environment Simulation, School of Environment, Beijing Normal University, Beijing 100875, China \\ Correspondence should be addressed to Enjun Ma; maej.ccap@igsnrr.ac.cn
}

Received 17 July 2013; Accepted 28 August 2013

Academic Editor: Xiangzheng Deng

Copyright (c) 2013 Enjun Ma et al. This is an open access article distributed under the Creative Commons Attribution License, which permits unrestricted use, distribution, and reproduction in any medium, provided the original work is properly cited.

\begin{abstract}
The afforestation is one of the most noticeable human activities that affect the climate through influencing not only the carbon sink but also the thermal properties of the land surface. This research accessed the potential effects of artificial vegetation change on the regional climate in Jiangxi Province, China. Based on simulation with the Weather Research and Forecasting (WRF) model, a comparative analysis was carried out on the future temperature and precipitation under four hypothetical vegetation cover scenarios. The simulation results indicated that the vegetation change would have significant effects on the regional climate. The simulated effects of annual average temperature showed a decreasing order: evergreen broadleaf $>$ evergreen needleleaf $>$ deciduous needleleaf $>$ deciduous broadleaf, and the effects of annual average precipitation of the evergreen forests would be bigger than those of the deciduous forests. The deciduous forests play a positive role in decreasing the annual average temperature, while the evergreen forests promote the annual average temperature rise. Besides, the expansion of deciduous forests may result in severe drought in the summer in Jiangxi Province. These conclusions are of important policy implication to the future afforestation in Jiangxi Province, China, and other regions of the world.
\end{abstract}

\section{Introduction}

The biogeochemical impacts of land use and land cover change (LUCC) on the climate through changing the chemical composition of the atmosphere have been greatly concerned and widely studied [1-5]. Impacts of LUCC on the regional and global climate can be divided into two major categories: biogeochemical and biogeophysical impacts $[1,6]$. The biogeophysical processes driven by LUCC directly affect the physical properties of the land surface, which determine the absorption and emission of energy at the Earth's surface $[2,3]$. Change of the land surface albedo can alter the absorption rate of solar radiation and consequently influence the energy availability $[4,5]$. Characteristics of vegetation transpiration on the land surface greatly affect how the energy received by the land surface is partitioned into the latent and sensible heat fluxes [7]. The vegetation type affects the surface roughness and consequently influences the transfer of local momentum and heat $[8,9]$. The vegetation increase/decrease exerted negative effects locally, and the effects were stronger in growth season than those in nongrowth season [10]. Recently, Jiangxi Province has many forests area and makes a lot of projects of afforestation, such as Green for Grain Project started in 2000 in Jiangxi Province. In 2011, Jiangxi makes a "one big four small" project of afforestation to achieve Green. As we know, these projects influence land use conversion and climate change $[11,12]$. In addition, some researches have indicated that the biogeophysical effects of LUCC on the climate may be more important than the biogeochemical effects $[13,14]$. The assessment of potential effects of artificial vegetation change on the regional climate in Jiangxi Province is meaningful for climate change mitigation and sustainable land management.

Afforestation is one of the most noticeable human activities that affect the climate through influencing not only the carbon sink but also the thermal properties of the land 
surface [15]. Zhang et al. (2012) research results show that the surface albedo decreased by $0.01-0.03$ due to conversions from grassland to cropland in the Northeast China Plain and it increased by $0.005-0.015$ due to conversions from forests to cropland in the surrounding mountain. As a consequence, the climate was warmed in the spring, autumn, and winter. In summer, effects of surface albedo changes on climate were closely associated with moisture dynamics, such as evapotranspiration and cloud, instead of being merely determined by surface radiation budget. The simulated summer climatic effects have large uncertainties [16]. Since Charney (1975) first studied the land use change and its influence on the climate, a number of researches have been implemented in the past decades, most of which focused on the tropical rainforest biome in South America, Africa, and Southeast Asia [17-23]. For example, Bonan et al. (1992) and Foley et al. (1996) explored the impacts of the boreal forest on the climate and found that there are some feedbacks that play a role in changing the climate as a result of changes of the difference between the land surface albedos of the boreal forest and bare snow [7, 24]. Besides, some researchers found that afforestation leads to greater evapotranspiration and consequently causes an increase of the latent heat flux [25-29]. Snyder et al. (2004) investigated the role of different vegetation types in the climate system using a coupled atmosphere-biosphere model, CCM3-IBIS, and they found that the global precipitation was most greatly affected by the removal of the savanna vegetation when including the areas of vegetation removal, while removal of the tropical forest most greatly influenced the global precipitation when excluding the areas of vegetation removal [30]. The research of Avissar and Werth (2005) showed that the combined effects of deforestation of three tropical regions caused a significant decrease of precipitation in California in the winter and seemed to lead to a cumulative enhancement of precipitation during the summer in the southern tip of the Arabian Peninsula [31]. In addition, the model-based researches showed that the afforestation at the low latitudes makes the global temperature decrease to some extent, while that at the middle latitudes leads to negligible change or increase of the global temperature, and the afforestation at high latitudes makes it increase to some degree [28, 29, 32, 33]. Bonan (2008) showed that the forests in the world influence the climate through physical, chemical, and biological processes that affect the planetary energetics, hydrologic cycle, and atmospheric composition. Besides, they found that the tropical, temperate, and boreal reforestation and afforestation alleviate the global warming through the carbon sequestration, and the biogeophysical feedbacks can enhance or weaken this negative climatic effect [34]. Boucher et al. (2012) presented a first glimpse at the extent to which the afforestation of boreal open woodlands (OWs) in Québec can provide large emitters with eventually substantial and efficient offset potential for Greenhouse Gas (GHG), especially those emitters tied up with incompressible GHG emissions [35]. Sharma and Huang (2012) performed regional climate simulations for Arizona, a region with complicated terrain, and the dependence of the simulated precipitation on the model accuracy was explored with the climate downscaling experiments using the Weather
Research and Forecasting (WRF) model [36]. Tang et al. and Yerramilli et al. showed that the variability and predictability of climate change are the core component of the climate dynamics $[37,38]$. In summary, it is in disputable that the change of vegetation types along with afforestation will lead to the regional climate change.

The forest coverage in Jiangxi Province had exceeded $63.1 \%$ by 2010 , which is much higher than the national average level (lower than 20\%) [11]. The area of needleleaved forests reaches 5.65 million $\mathrm{hm}^{2}$, accounting for $68.1 \%$ of the arbor area and $52.7 \%$ of the total forest area in Jiangxi Province, and it will continue to increase due to afforestation. Meanwhile, the broad-leaved forest recovery will be one of the competitors of the needle-leaved forest expansion due to the favorable water and heat resources. This research aims to predict the potential effects of artificial vegetation change on the regional climate in Jiangxi Province. Based on the simulation with WRF model, a comparative analysis was carried out on the future temperature and precipitation under four hypothetical vegetation cover scenarios, under which the forests are deciduous broadleaf, deciduous needleleaf, evergreen broadleaf, and evergreen needleleaf. The scheme of simulation with the WRF model is described in Section 2. This section also introduced the atmospheric forcing dataset and a hypothetic forest pattern dataset of different vegetation types used in the simulation. The results and discussions are provided in Section 3 and the final section concludes.

\section{Data and Methodology}

The WRF model is a state-of-the-art atmospheric simulation system based on the Fifth-Generation Penn State/NCAR Mesoscale Model (MM5) [39]. This mesoscale model was used to investigate the change of temperature and precipitation driven by future afforestation in this study.

2.1. Simulation Scheme. There are currently five kinds of forests in Jiangxi Province, that is, the deciduous broadleaf forest, deciduous needleleaf forest, evergreen broadleaf forest, evergreen needleleaf forest, and mixed forest. The needleleaf forests have expanded due to the afforestation in this region; however, the broadleaf forests are recovering owing to the suitable climatic conditions. On the whole, the forest change in Jiangxi Province is characterized by the competition between the needleleaf forests and the broadleaf forests. To cover the potential effects of the forest vegetation change on regional climate, four hypothetical vegetation cover scenarios were designed in this study, including the scenarios of deciduous broadleaf (DB), deciduous needleleaf (DN), evergreen broadleaf (EB), and evergreen needleleaf (EN), under which the forests are all deciduous broadleaf, deciduous needleleaf, evergreen broadleaf, and evergreen needleleaf, respectively. The forest pattern in year 2000 was regarded as the baseline scenario (BL). The effects of afforestation on the regional climate can be measured with the differences of the simulation results under the four hypothetical scenarios and the baseline scenario:

$$
E_{i}=R_{i}-r_{i}
$$


where $i$ refers to the precipitation and temperature; $E_{i}$ is the effects of the vegetation change on the climate under the four hypothetical scenarios; $R_{i}$ is the simulation results under the four hypothetical extreme vegetation cover scenarios; and $r_{i}$ is the simulation results under the baseline scenario.

2.2. Atmospheric Forcing Data. The National Centers for Environmental Prediction (NCEP) Global Forecast System (GFS) is a global spectral data assimilation and forecast model system giving atmospheric variables every 6 hours (00:00, 06:00, 12:00, and 18:00 UTC) at 26 levels with a resolution of 0.5 degree. The NCEP GFS final (FNL) gridded analysis datasets for the period from Jan 2000 until the current day can be obtained. For the applications in this work, the data of NCEP GFSFNL version of 2010 have been used as the atmospheric forcing dataset of the WRF model.

2.3. Underlying Surface Data. The underlying surface data of the scenarios of DB, DN, EB, and EN as well as BL are needed in the scenario-based simulation. The underlying surface data of the scenario of $\mathrm{BL}$ were derived from the dataset of National Basic Research Program of China. The dataset was originally established with the $1 \mathrm{~km} \times 1 \mathrm{~km}$ grid data based on the remotely sensed satellite imagery and ground information of year 2000 with the land use and land cover classification system of the United States Geological Survey (USGS). In this study, the $1 \mathrm{~km} \times 1 \mathrm{~km}$ grid data were first transformed into the grid data of $5 \mathrm{~km} \times 5 \mathrm{~km}$ by resampling the data. The underlying surface data suggests that more than $40 \%$ of the areas in Jiangxi Province (2717 pixels) were covered by the forests (Figure 1) and about 30\% of them were covered by the broadleaf forests, while the needleleaf forests account for more than $52 \%$ of the total forest area.

The underlying surface data of DB, DN, EB, and EN were generated by replacing all the forests with one specific type of forests. For instance, the underlying surface data of DB were generated by replacing all the deciduous needleleaf forests, evergreen broadleaf forests, evergreen needleleaf forests, and mixed forests with the deciduous broadleaf forests, and consequently all the forest area in Jiangxi Province is covered by the deciduous broadleaf forests under the scenario of $\mathrm{BD}$. And similarly, the underlying surface data of DN, EB, and EN were generated by altering the property of pixels.

\section{Results and Discussion}

The simulation results of the temperature and precipitation in Jiangxi Province in 2010 under the scenarios of DB, DN, $\mathrm{EB}$, and $\mathrm{EN}$ as well as BL were finally obtained. As were described above, the effects of afforestation on the climate were measured with the differences between the simulation results under the four hypothetical scenarios and the baseline scenario as follows.

3.1. Effects on the Annual Average Temperature. The simulation results showed that there were significant effects of the vegetation change on the annual average temperature in

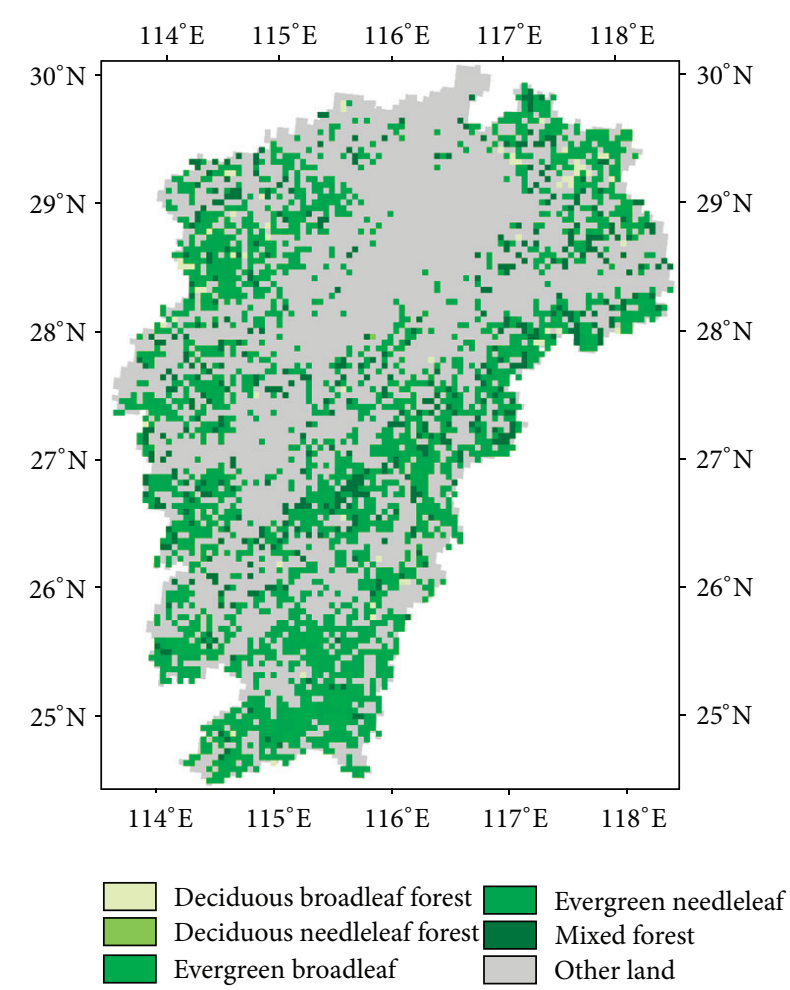

FIgURE 1: Forest area of Jiangxi Province in 2000.

Jiangxi Province. Among the results under the four hypothetical extreme scenarios, there were overall cooling effects under the scenarios of DB and DN, while warming effects under the scenarios of EB and EN (Figure 2). The statistics indicates that the deciduous broadleaf expansion under the scenario of DB will make the annual average temperature decrease by $0.08^{\circ} \mathrm{C}$. This cooling effect will mainly happen in the southern part of Jiangxi Province. For some areas there, the annual average temperature will even decline by more than $0.2^{\circ} \mathrm{C}$. By comparison, the expansion of deciduous needleleaf forests under the scenario of DN only shows slight cooling effects. According to the simulation results, the cooling effects also mainly happen in the southern part of Jiangxi Province and are not as significant as those under the scenario of $\mathrm{DB}$. The results under the scenario of $\mathrm{DN}$ indicate there are some warming effects in the areas near the north and west boundary of Jiangxi Province. The overall effects of expansion of deciduous needleleaf forests make the annual average temperature decrease by $0.02^{\circ} \mathrm{C}$ under the scenario of DN.

The simulation results indicated that the spatial pattern of the warming effects under the scenario of $\mathrm{EB}$ is consistent with the pattern of forests in Jiangxi Province, and the evergreen broadleaf expansion will make the annual average temperature increase by $0.03^{\circ} \mathrm{C}$ (Figure 2). The annual average temperature under the scenario of EN will increase by $0.01^{\circ} \mathrm{C}$ more than that under the scenario of BL. In summary, the deciduous forest plays a positive role in decreasing the annual average temperature while evergreen forest contributes to the increase of annual average temperature, and the effect of 




(a)

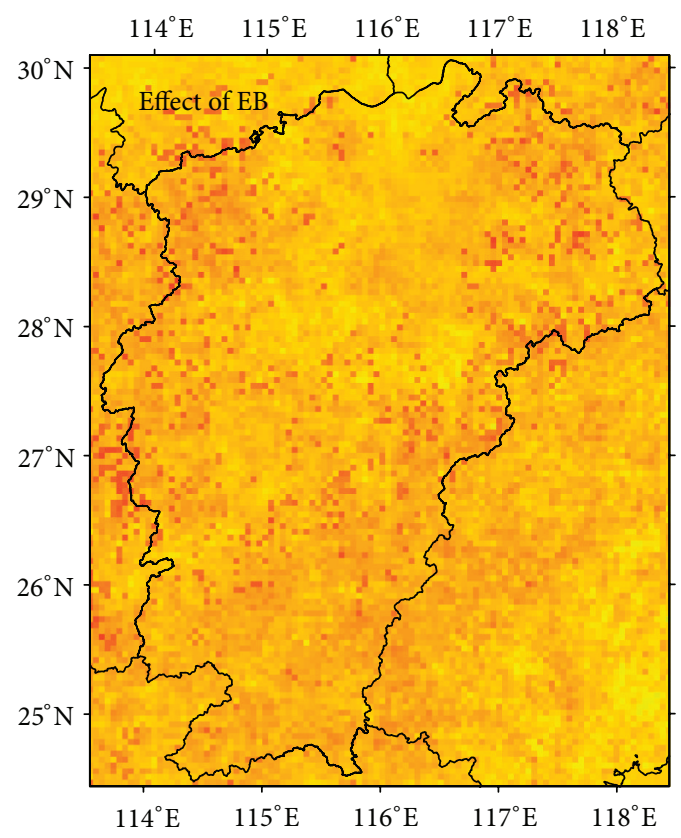

(c)

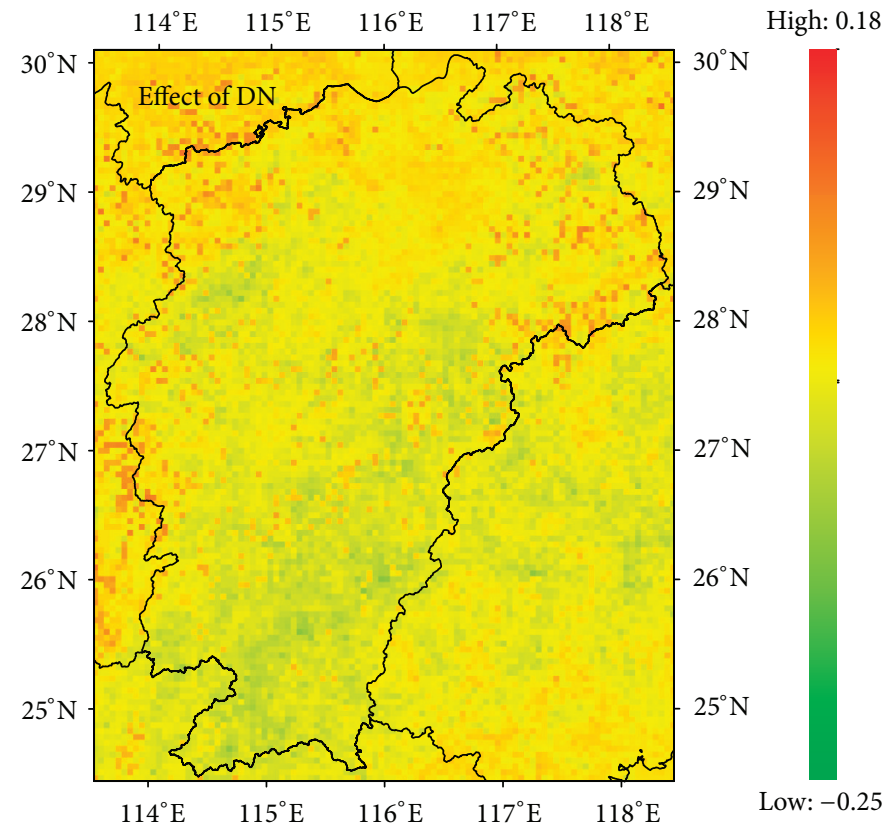

(b)

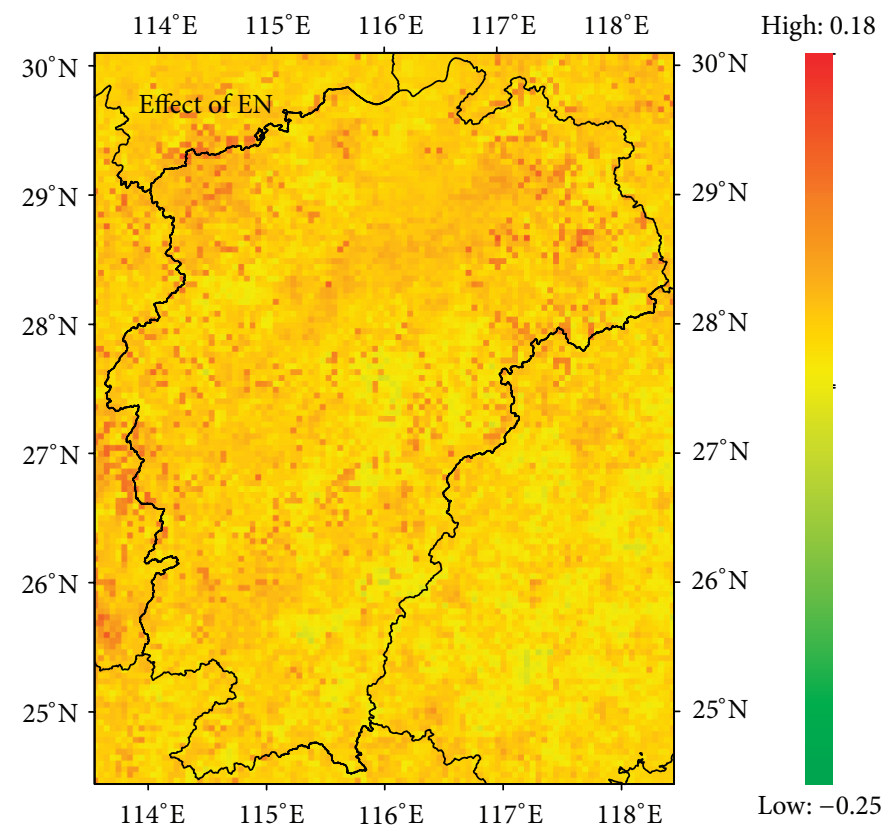

(d)

FIGURE 2: Simulated effects of afforestation on the annual average temperature (measured in degrees Celsius) in Jiangxi Province.

needleleaf forest expansion on annual average temperature is much more significant than that of broadleaf forest. This may be due to the differences between the thermal properties of the deciduous and evergreen forests.

3.2. Effects on the Annual Average Precipitation. The expansion of deciduous forests leads to significant change of the spatial pattern of the annual average precipitation in Jiangxi
Province. The simulation results under the scenario of DB showed that the expansion of deciduous broadleaf forests will make the annual average precipitation in the southeast part of Jiangxi Province decrease by more than $400 \mathrm{~mm}$ (Figure 3). Besides, the annual average precipitation in the northwest part of Jiangxi Province will also increase by more than $250 \mathrm{~mm}$. However, the expansion of the deciduous broadleaf forests will make the overall annual average precipitation in the simulation area decrease by $47 \mathrm{~mm}$ under the scenario 


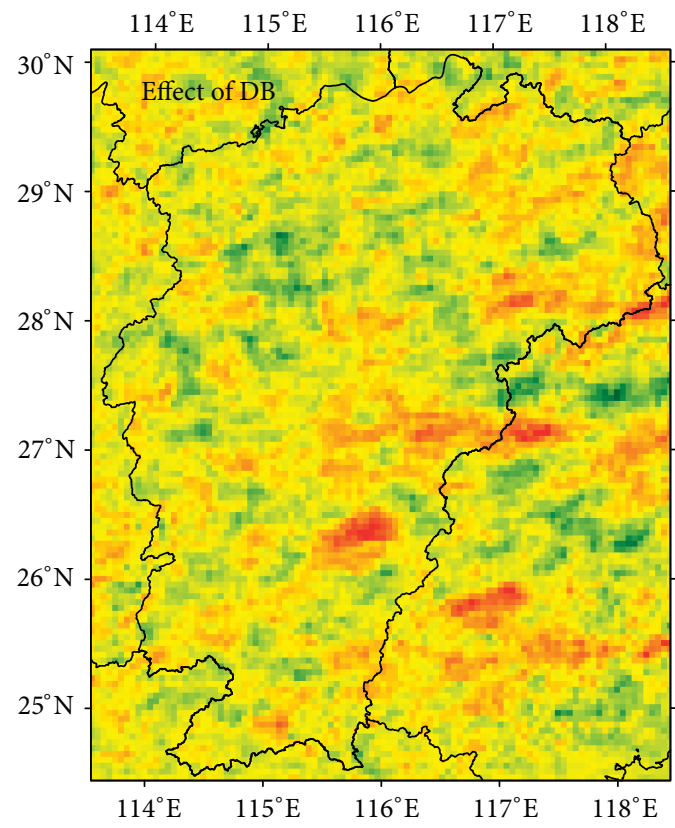

(a)



(c)


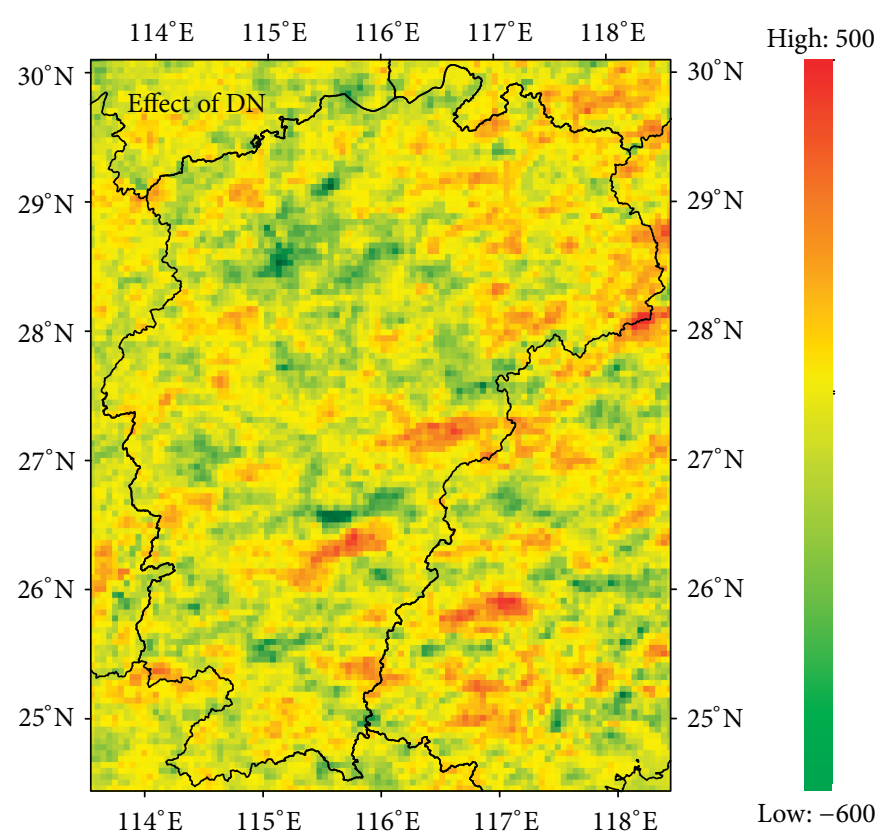

(b)

High: 500

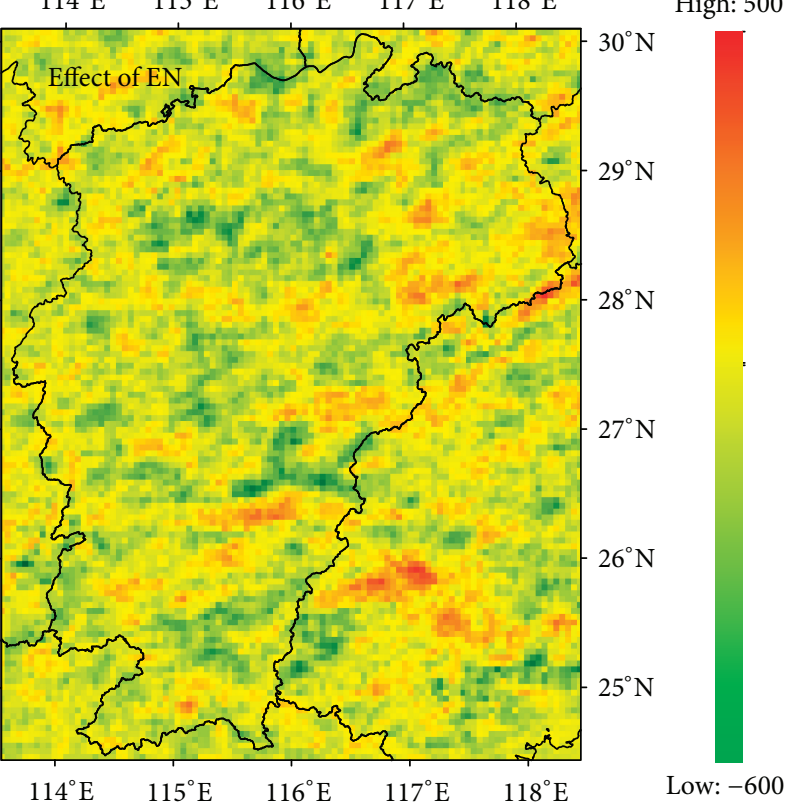

(d)

FIGURE 3: Simulated effects of afforestation on the annual average precipitation (measured in milimeters) in Jiangxi Province.

of DB. By comparison, the drought effects of the deciduous needleleaf forest expansion under the scenario of DN area are little slighter than those under the scenario of $\mathrm{DB}$, and it will make the annual average precipitation decrease by $33 \mathrm{~mm}$ in the study area on the whole. Moreover, the spatial pattern of the climatic effects under the scenario of DN is similar to that under the scenario of DB.
In comparison, the simulation results under the scenarios of EB and EN indicated that the overall effects of the evergreen forest expansion on the annual average precipitation are not as significant as those under the scenarios of $\mathrm{DB}$ and DN. In most part of Jiangxi Province, the evergreen forest expansion will make the annual average precipitation increase by $50 \mathrm{~mm}$ to $200 \mathrm{~mm}$ under the scenarios of $\mathrm{EB}$ 
TABLE 1: Simulated effects of afforestation on the monthly average temperature in Jiangxi Province (measured in degrees Celsius).

\begin{tabular}{lcccccccc}
\hline \multirow{2}{*}{ Month } & \multicolumn{2}{c}{ DB } & \multicolumn{2}{c}{ DN } & \multicolumn{2}{c}{ EB } & \multicolumn{2}{c}{ EN } \\
& Mean & Std. & Mean & Std. & Mean & Std. & Mean & Std. \\
\hline 1 & -0.12 & 0.09 & -0.06 & 0.06 & 0.05 & 0.06 & 0.03 & 0.05 \\
2 & -0.09 & 0.07 & -0.05 & 0.06 & 0.03 & 0.05 & 0.02 & 0.05 \\
3 & -0.07 & 0.07 & 0.00 & 0.05 & 0.05 & 0.05 & 0.02 & 0.05 \\
4 & -0.07 & 0.06 & -0.03 & 0.05 & 0.02 & 0.04 & 0.01 & 0.04 \\
5 & -0.08 & 0.07 & -0.02 & 0.05 & 0.01 & 0.05 & -0.01 & 0.05 \\
6 & -0.08 & 0.08 & -0.03 & 0.06 & 0.01 & 0.06 & 0.00 & 0.06 \\
7 & -0.05 & 0.08 & -0.02 & 0.07 & 0.00 & 0.07 & -0.01 & 0.07 \\
8 & -0.06 & 0.08 & -0.01 & 0.07 & 0.00 & 0.06 & -0.01 & 0.07 \\
9 & -0.08 & 0.08 & -0.03 & 0.06 & 0.00 & 0.06 & -0.01 & 0.06 \\
10 & -0.07 & 0.06 & -0.01 & 0.04 & 0.03 & 0.04 & 0.01 & 0.04 \\
11 & -0.08 & 0.07 & 0.00 & 0.06 & 0.05 & 0.06 & 0.02 & 0.05 \\
12 & -0.07 & 0.07 & 0.00 & 0.05 & 0.05 & 0.06 & 0.03 & 0.05 \\
\hline
\end{tabular}

and EN (Figure 3). The drought effects under the scenarios of EB and EN will mainly happen in the area near the east boundary of Jiangxi Province. The simulation results show that the annual average precipitation will decrease by $2.6 \mathrm{~mm}$ and $3.9 \mathrm{~mm}$ under the scenarios of EB and EN, respectively. On the whole, the deciduous forest expansion may aggravate the drought, while the expansion of evergreen forests may increase the annual average precipitation in most regions in Jiangxi Province. So the expansion of evergreen forests is more favorable than the expansion of deciduous forests since the seasonal drought is one of the main problems that restrains the agricultural production in Jiangxi Province.

3.3. Effects on the Monthly Climate. The effects of afforestation on the monthly average temperature vary from month to month under all the four scenarios (Table 1). Under the scenario of $\mathrm{DB}$, the deciduous broadleaf forest expansion will result in a relatively stable decrease of the monthly average temperature in most months, by $0.07^{\circ} \mathrm{C}$ to $0.08^{\circ} \mathrm{C}$; the temperature will decrease the most in January and least in July, by $0.12^{\circ} \mathrm{C}$ and $0.05^{\circ} \mathrm{C}$, respectively. By comparison, there is a slighter decrease of the monthly average temperature due to the deciduous needleleaf forest expansion under the scenario of DN than that under the scenario of $\mathrm{DB}$, and the monthly average temperature will decrease by no more than $0.03^{\circ} \mathrm{C}$ from April to October. The afforestation even has no effects on monthly average temperature in March, November, and December under the scenario of DN.

In contrast to the effects under the scenarios of $\mathrm{DB}$ and $\mathrm{DN}$, the evergreen broadleaf forest expansion under the scenario of EB will lead to some increase of the monthly average temperature (Table 1). The simulation results show that the monthly average temperature will increase by $0.03^{\circ} \mathrm{C}$ to $0.05^{\circ} \mathrm{C}$ from October to March under this scenario and that it will decrease by $0.01^{\circ} \mathrm{C}$ to $0.02^{\circ} \mathrm{C}$ in April, May, and June due to the evergreen broadleaf forest expansion. Besides, there are no significant effects of the evergreen broadleaf forest expansion on the monthly average temperature in July, August, and September. There are more complex effects of
TABLE 2: Simulated effects of afforestation on albedo in Jiangxi Province (magnified by $10^{-3}$ ).

\begin{tabular}{lcccccccc}
\hline \multirow{2}{*}{ Month } & \multicolumn{2}{c}{ DB } & \multicolumn{2}{c}{ DN } & \multicolumn{2}{c}{ EB } & \multicolumn{2}{c}{ EN } \\
& Mean & Std. & Mean & Std. & Mean & Std. & Mean & Std. \\
\hline 1 & 11.31 & 30.52 & 3.59 & 27.43 & -7.61 & 28.73 & -7.61 & 28.73 \\
2 & 11.56 & 30.37 & 3.75 & 27.17 & -7.57 & 28.36 & -7.56 & 28.39 \\
3 & 11.51 & 31.18 & 3.70 & 28.05 & -7.71 & 29.26 & -7.71 & 29.25 \\
4 & 11.75 & 27.83 & 3.93 & 24.15 & -6.57 & 25.03 & -6.57 & 25.03 \\
5 & 12.05 & 22.80 & 4.24 & 17.93 & -4.78 & 18.16 & -4.78 & 18.16 \\
6 & 12.35 & 20.04 & 4.54 & 13.99 & -3.58 & 13.54 & -3.58 & 13.54 \\
7 & 12.34 & 19.75 & 4.52 & 13.59 & -3.47 & 13.12 & -3.47 & 13.12 \\
8 & 12.33 & 19.92 & 4.52 & 13.84 & -3.54 & 13.39 & -3.54 & 13.39 \\
9 & 12.31 & 20.44 & 4.49 & 14.60 & -3.77 & 14.27 & -3.77 & 14.27 \\
10 & 11.80 & 24.03 & 3.99 & 19.62 & -5.31 & 20.22 & -5.31 & 20.22 \\
11 & 11.58 & 27.10 & 3.77 & 23.40 & -6.40 & 24.40 & -6.40 & 24.40 \\
12 & 11.26 & 28.63 & 3.57 & 25.42 & -7.10 & 26.62 & -7.08 & 26.63 \\
\hline
\end{tabular}

expansion of the evergreen needleleaf forests under the scenario of EN, which makes the monthly average temperature decrease from May to September and increase from October to April (Table 1). On the whole, the variation of the monthly average temperature change under the scenarios of DN, EB, and EN is similar to that under the scenario of DB.

Afforestation can affect the monthly average temperature via multiple ways such as albedo, potential evapotranspiration, and leaf area index. Considering the plentiful water and heat resources in Jiangxi province, albedo is most likely to be the principal cause resulting in the monthly average temperature changes. The changes of albedo under all the four scenarios are provided to help identify the reasons of monthly average temperature changes (Table 2). A larger increase in albedo corresponds to a severer decrease in monthly average temperature. It implies that the cooling effect is from low surface net radiation caused by high albedo under the scenarios of DB and DN. And on the contrary, the declines of albedo under the scenarios of EB and EN may be the major causes of monthly average temperature increase in Jiangxi Province. The variation of monthly average temperature change also has a convergence trend with that of albedo change. The correlation coefficient of monthly average temperature change and albedo change reaches -0.77 , which also implies that the temperature changes are mainly derived from the changes of albedo driven by afforestation.

The effects of afforestation on the monthly average precipitation are more significant than those on the monthly average temperature. The precipitation in Jiangxi Province will decrease greatly in the summer under the scenarios of DB and DN (Table 3). Under the scenario of DB, the monthly average precipitation will decrease by $10.63 \mathrm{~mm}, 11.50 \mathrm{~mm}$, and $8.63 \mathrm{~mm}$ in June, July, and August, respectively. Although the decrement of the monthly average precipitation is smaller than that under the scenario of DN, it still reaches $10.42 \mathrm{~mm}$ in July. The drought effects of the deciduous forest expansion will last for all the year under the scenarios of DB and DN. The decrease of the monthly average precipitation may restrain the agricultural production in Jiangxi Province. By contrast, 
TABLE 3: Simulated effects of afforestation on the monthly average precipitation in Jiangxi Province (measured in milimeters).

\begin{tabular}{lcccccccc}
\hline \multirow{2}{*}{ Month } & \multicolumn{2}{c}{ DB } & \multicolumn{2}{c}{ DN } & \multicolumn{2}{c}{ EB } & \multicolumn{2}{c}{ EN } \\
& Mean & Std. & Mean & Std. & Mean & Std. & Mean & Std. \\
\hline 1 & -0.16 & 5.01 & -0.18 & 4.96 & -0.06 & 5.09 & -0.01 & 4.92 \\
2 & -1.03 & 10.98 & -0.89 & 11.85 & 0.03 & 10.60 & 0.25 & 10.65 \\
3 & -0.57 & 10.43 & -0.86 & 11.87 & 0.07 & 10.79 & 0.20 & 9.93 \\
4 & -2.39 & 21.93 & -1.77 & 20.83 & 0.20 & 22.28 & 1.44 & 22.67 \\
5 & -5.10 & 43.83 & -4.01 & 41.78 & 0.34 & 48.23 & -0.99 & 46.52 \\
6 & -10.63 & 61.72 & -6.37 & 55.74 & -1.20 & 57.79 & -0.34 & 55.14 \\
7 & -11.50 & 59.29 & -10.42 & 61.17 & -0.89 & 61.26 & -2.95 & 60.15 \\
8 & -8.63 & 42.27 & -4.86 & 42.42 & -1.29 & 40.29 & -1.89 & 42.31 \\
9 & -6.79 & 39.63 & -3.48 & 39.87 & 0.11 & 40.48 & 0.06 & 38.69 \\
10 & -0.29 & 9.19 & -0.29 & 8.96 & 0.09 & 8.74 & 0.23 & 9.01 \\
11 & -0.25 & 1.40 & -0.21 & 1.35 & 0.03 & 1.30 & 0.07 & 1.32 \\
12 & -0.03 & 1.77 & -0.08 & 1.72 & -0.03 & 1.77 & 0.02 & 1.69 \\
\hline
\end{tabular}

there are slight effects of the evergreen forest expansion on the monthly average precipitation under the scenarios of EB and $\mathrm{EN}$ (Table 3). The monthly average precipitation will decrease most greatly in August under the scenario of EB, with a decrement of $1.29 \mathrm{~mm}$, while it will decrease by no more than $3 \mathrm{~mm}$ under the scenario of EN. In summary, there is no significant difference for variation of the monthly average temperature change among the scenarios of DB, DN, EB, and EN.

Above all, the effects of annual average temperature show a decreasing order: $\mathrm{EB}>\mathrm{EN}>\mathrm{DN}>\mathrm{DB}$. By comparison, the expansion of deciduous needleleaf forests under the scenario of DB shows evident cooling effects, because there are the highest albedos under the scenario of DB. According to the simulation results, the cooling effects mainly happen in the southern part of Jiangxi Province and the effects of annual average precipitation of the evergreen forests are bigger than those of the deciduous forests.

\section{Conclusions}

This study analyzed the impacts of afforestation on the regional climate at different temporal scales in Jiangxi Province with a scenario-based research. The main conclusions could be summarized as follows.

(i) The deciduous forest expansion plays a positive role in decreasing the annual average temperature, while the evergreen forest expansion makes the annual average temperature increase. On the whole, the effects of the needleleaf forest expansion on the annual average temperature are not as significant as that of the broadleaf forest. The expansion of deciduous forests may aggravate the seasonal drought in Jiangxi Province, while the expansion of evergreen forests is more favorable since it may increase the annual average precipitation in most parts of Jiangxi Province. (ii) There are significant effects of afforestation, especially the deciduous forest expansion, on the monthly average precipitation. There is only slight change of the monthly average temperature caused by afforestation. Moreover, the deciduous forest expansion may result in severe drought at the local scale in the summer in Jiangxi Province.

\section{Conflict of Interests}

The authors declare that there is no conflict of interests regarding the publication of this paper.

\section{Acknowledgments}

This research was supported by the Project of the National Natural Science Foundation of China (Grant no. 41071343), the National Basic Research Program of China (973 Program) (Grant no. 2010CB950900), and the Exploratory Forefront Project for the Strategic Science Plan in IGSNRR, CAS.

\section{References}

[1] P. Kabat, M. Claussen, P. A. Dirmeyer et al., Vegetation, Water, Humans and the Climate: A New Perspective on an Interactive System, Springer, Heidelberg, Germany, 2003.

[2] J. A. Foley, R. DeFries, G. P. Asner et al., "Global consequences of land use," Science, vol. 309, no. 5734, pp. 570-574, 2005.

[3] L. Dümenil-Gates and S. Liess, "Impacts of deforestation and afforestation in the Mediterranean region as simulated by the MPI atmospheric GCM," Global and Planetary Change, vol. 30, no. 3-4, pp. 309-328, 2001.

[4] R. A. Betts, "Biogeophysical impacts of land use on presentday climate: near-surface temperature change and radiative forcing," Atmospheric Science Letters, vol. 2, no. 1, pp. 39-51, 2001.

[5] J. Feddema, K. Oleson, G. Bonan et al., "A comparison of a GCM response to historical anthropogenic land cover change and model sensitivity to uncertainty in present-day land cover representations," Climate Dynamics, vol. 25, no. 6, pp. 581-609, 2005.

[6] X. Z. Deng, C. H. Zhao, and H. M. Yan, "Systematic modeling of impacts of land use and land cover changes on regional climate: a review," Advances in Meteorology, vol. 2013, Article ID 317678, 10 pages, 2013.

[7] G. B. Bonan, D. Pollard, and S. L. Thompson, "Effects of boreal forest vegetation on global climate," Nature, vol. 359, no. 6397, pp. 716-718, 1992.

[8] K. McGuffie, A. Henderson-Sellers, H. Zhang, T. B. Durbidge, and A. J. Pitman, "Global climate sensitivity to tropical deforestation," Global and Planetary Change, vol. 10, no. 1-4, pp. 97128, 1995.

[9] M. Hoogmoed, S. C. Cunningham, J. R. Thomson, P. J. Baker, J. Beringer, and T. R. Cavagnaro, "Does afforestation of pastures increase sequestration of soil carbon in Mediterranean climates?" Agriculture, Ecosystems \& Environment, vol. 159, pp. 176-183, 2012.

[10] Q. S. Ge, X. Z. Zhang, and J. Y. Zheng, "Simulated effects of vegetation increase/decrease on temperature changes from 
1982 to 2000 across the Eastern China," International Journal of Climatology, 2013.

[11] X. Deng, J. Huang, E. Uchida, S. Rozelle, and J. Gibson, "Pressure cookers or pressure valves: do roads lead to deforestation in China?" Journal of Environmental Economics and Management, vol. 61, no. 1, pp. 79-94, 2011.

[12] X. Deng, Y. Zhao, F. Wu, Y. Lin, Q. Lu, and J. Dai, "Analysis of the trade-off between economic growth and the reduction of nitrogen and phosphorus emissions in the Poyang Lake Watershed, China," Ecological Modelling, vol. 222, no. 2, pp. 330336, 2011.

[13] R. A. Pielke, G. Marland, R. A. Betts et al., "The influence of land-use change and landscape dynamics on the climate system: relevance to climate-change policy beyond the radiative effect of greenhouse gases," Philosophical Transactions of the Royal Society A, vol. 360, no. 1797, pp. 1705-1719, 2002.

[14] G. Marland, R. A. Pielke Sr., M. Apps et al., "The climatic impacts of land surface change and carbon management, and the implications for climate-change mitigation policy," Climate Policy, vol. 3, no. 2, pp. 149-157, 2003.

[15] G. Nabuurs, O. Masera, K. Andrasko et al., "Climate change 2007: mitigation," in Contribution of Working Group III to the Fourth Assessment Report of the Intergovernmental Panel on Climate Change, B. Metz, O.R. Davidson, P.R. Bosch, R. Dave, and L.A. Meyer, Eds., Cambridge University Press, Cambridge, UK, 2007.

[16] X. Z. Zhang, W. C. Wang, X. Q. Xiu, Y. Ye, and J. Y. Zheng, "Agriculture development-induced surface albedo changes and climatic implications across Northeastern China," Chinese Geographical Science, vol. 22, no. 3, pp. 264-277, 2012.

[17] J. G. Charney, "Dynamics of deserts and droughts in the Sahel," Quarterly Journal of the Royal Meteorological Society, vol. 101, no. 428, pp. 193-202, 1975.

[18] R. E. Dickinson and A. Henderson-Sellers, "Modelling tropical deforestation: a study of GCM land/surface parametrizations," Quarterly Journal, vol. 114, no. 480, pp. 439-462, 1988.

[19] C. A. Nobre, P. J. Sellers, and J. Shukla, "Amazonian deforestation and regional climate change," Journal of Climate, vol. 4, no. 10, pp. 957-988, 1991.

[20] A. Henderson-Sellers, R. E. Dickinson, T. B. Durbidge, P. J. Kennedy, K. McGuffie, and A. J. Pitman, "Tropical deforestation: modeling local- to regional-scale climate change," Journal of Geophysical Research, vol. 98, no. 4, pp. 7289-7315, 1993.

[21] Y. C. Sud, G. K. Walker, J.-H. Kim, G. E. Liston, P. J. Sellers, and W. K.-M. Lau, "Biogeophysical consequences of a tropical deforestation scenario: a GCM simulation study," Journal of Climate, vol. 9, no. 12, pp. 3225-3247, 1996.

[22] J. Lean and P. R. Rowntree, "Understanding the sensitivity of a GCM simulation of Amazonian deforestation to the specification of vegetation and soil characteristics," Journal of Climate, vol. 10, no. 6, pp. 1216-1235, 1997.

[23] C. Delire, P. Behling, M. T. Coe et al., "Simulated response of the atmosphere-ocean system to deforestation in the Indonesian Archipelago," Geophysical Research Letters, vol. 28, no. 10, pp. 2081-2084, 2001.

[24] J. A. Foley, I. C. Prentice, N. Ramankutty et al., "An integrated biosphere model of land surface processes, terrestrial carbon balance, and vegetation dynamics," Global Biogeochemical Cycles, vol. 10, no. 4, pp. 603-628, 1996.

[25] A. Kleidon, K. Fraedrich, and M. Heimann, "A green planet versus a desert world: estimating the maximum effect of vegetation on the land surface climate," Climatic Change, vol. 44, no. 4, pp. 471-493, 2000.

[26] B. Govindasamy, P. B. Duffy, and K. Caldeira, "Land use changes and Northern Hemisphere cooling," Geophysical Research Letters, vol. 28, no. 2, pp. 291-294, 2001.

[27] L. Bounoua, R. DeFries, G. J. Collatz, P. Sellers, and H. Khan, "Effects of land cover conversion on surface climate," Climatic Change, vol. 52, no. 1-2, pp. 29-64, 2002.

[28] G. Bala, K. Caldeira, M. Wickett et al., "Combined climate and carbon-cycle effects of large-scale deforestation," Proceedings of the National Academy of Sciences of the United States of America, vol. 104, no. 16, pp. 6550-6555, 2007.

[29] A. Montenegro, M. Eby, Q. Mu et al., "The net carbon drawdown of small scale afforestation from satellite observations," Global and Planetary Change, vol. 69, no. 4, pp. 195-204, 2009.

[30] P. K. Snyder, C. Delire, and J. A. Foley, "Evaluating the influence of different vegetation biomes on the global climate," Climate Dynamics, vol. 23, no. 3-4, pp. 279-302, 2004.

[31] R. Avissar and D. Werth, "Global hydroclimatological teleconnections resulting from tropical deforestation," Journal of Hydrometeorology, vol. 6, no. 2, pp. 134-145, 2005.

[32] M. Claussen, V. Brovkin, and A. Ganopolski, "Biophysical versus biogeochemical feedbacks of large-scale land cover change," Geophysical Research Letters, vol. 28, no. 6, pp. 1011-1014, 2001.

[33] S. Gibbard, K. Caldeira, G. Bala, T. J. Phillips, and M. Wickett, "Climate effects of global land cover change," Geophysical Research Letters, vol. 32, no. 23, Article ID L23705, 4 pages, 2005.

[34] G. B. Bonan, "Forests and climate change: forcings, feedbacks, and the climate benefits of forests," Science, vol. 320, no. 5882, pp. 1444-1449, 2008.

[35] J. F. Boucher, P. Tremblay, S. Gaboury, and C. Villeneuve, "Can boreal afforestation help offset incompressible GHG emissions from Canadian industries?” Process Safety and Environmental Protection, vol. 90, no. 6, pp. 459-466, 2012.

[36] A. Sharma and H. P. Huang, "Regional climate simulation for Arizona: impact of resolution on precipitation," Advances in Meteorology, vol. 2012, Article ID 505726, 13 pages, 2012.

[37] Y. M. Tang, S. I. An, and W. S. Duan, "Climate variability and predictability at various time scales," Advances in Meteorology, vol. 2012, Article ID 857831, 1 page, 2012.

[38] A. Yerramilli, V. S. Challa, V. B. R. Dodla et al., "Simulation of surface ozone pollution in the central gulf coast region using WRF/Chem model: sensitivity to PBL and land surface physics," Advances in Meteorology, vol. 2010, Article ID 319138, 24 pages, 2010.

[39] G. A. Grell, J. Dudhia, and D. R. Stauffer, "Adescription of the fifth-generation PennState/NCAR mesoscale model (MM5)," NCAR Technical Note NCAR/TN-398+STR, NCAR, Boulder, Colo, USA, 1995. 



The Scientific World Journal
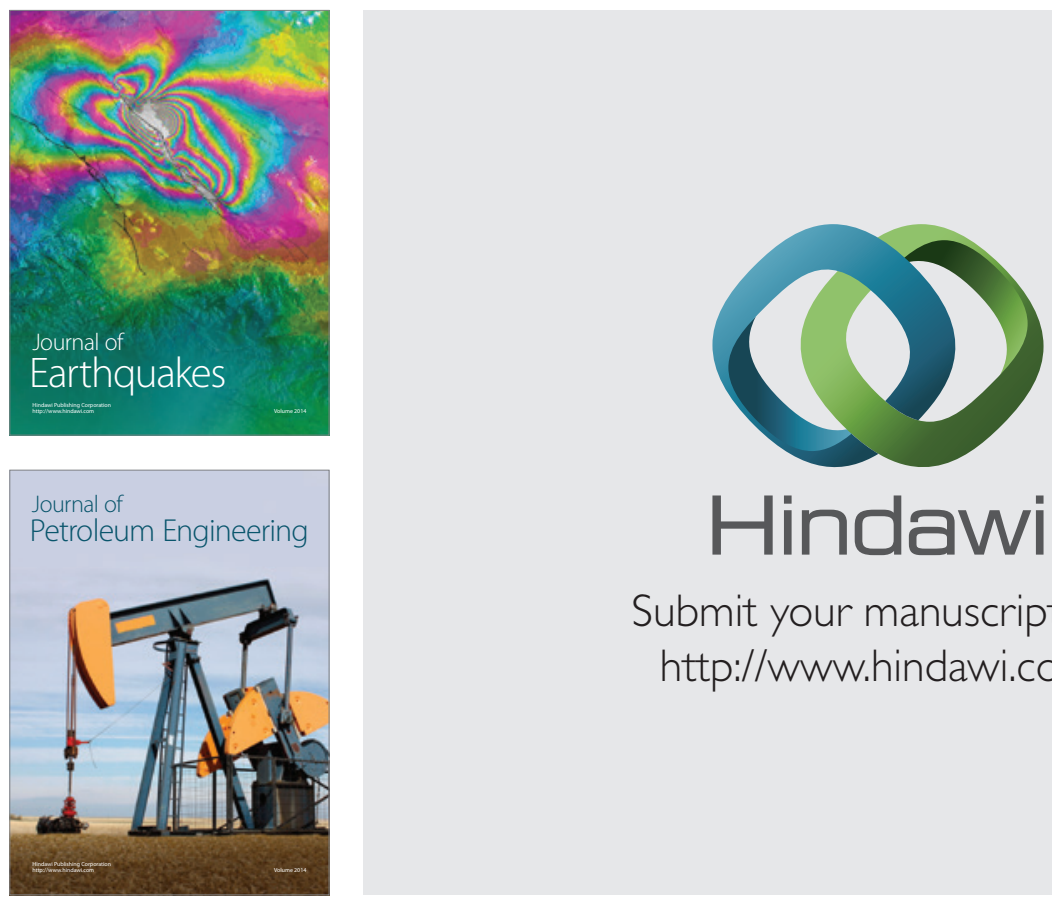

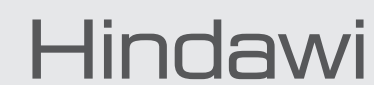

Submit your manuscripts at

http://www.hindawi.com

